\title{
Visual outcomes endorse surgery of patients with spheno-orbital meningioma with minimal visual impairment or hyperostosis
}

\author{
Amir H. Zamanipoor Najafabadi ${ }^{1}$ (D) $\cdot$ Stijn W. Genders ${ }^{2,3} \cdot$ Wouter R. van Furth $^{1}$
}

Received: 5 July 2020 / Accepted: 24 August 2020 / Published online: 4 September 2020

(C) The Author(s) 2020

\begin{abstract}
Abtract
Background Most spheno-orbital meningioma series span multiple decades, and predictors of visual outcomes have not yet been systemically assessed. We describe visual outcomes in a recent cohort and assess predictors of postoperative visual outcomes. Methods Consecutive case series operated by a team of a neurosurgeon and orbital surgeon between May 2015 and January 2019. Best corrected visual acuity (BCVA), visual fields (static perimetry), and relative proptosis were measured preoperatively and postoperatively at 3/6/12 months after which it was assessed yearly. Predictors were assessed with linear regression analysis. Results Nineteen patients (all WHO grade I) were operated by the pterional approach (median follow-up 2.4 years). Preoperative visual acuity deficits $(n=10)$ normalized in $70 \%$ and improved in $10 \%$ (median preoperative: 0.8 , postoperative: $1.2, p=0.021)$. Preoperative visual field deficits $(n=8)$ normalized in all patients (preoperative: $-6.5 \mathrm{~dB}$, postoperative: $-1.5 \mathrm{~dB}, p=0.008)$. Preoperative proptosis $(n=16)$ normalized in $44 \%$ and improved in $56 \%$ (preoperative: $5 \mathrm{~mm}$, postoperative: $2 \mathrm{~mm}, p<0.001$ ). BCVA and visual fields remained stable at longer follow-up in 95\% of patients, while $21 \%$ showed progression of proptosis. Predictors for worse longer-term (>12 months) BCVA were worse preoperative BCVA $(p=0.002)$ and diagnosis of multiple meningioma $(p=0.021)$. Predictors for worse longer-term visual fields were higher diameter of hyperostosis $(p=0.009)$ and higher Simpson grade $(p=0.032)$. Predictor for short-term (3 months) proptosis was preoperative proptosis $(p=0.006)$.

Conclusion We recommend surgery, even of patients with minimal visual impairment or hyperostosis, as patients who present with deteriorated visual function or extensive hyperostosis are less likely to have postoperative visual outcomes restored to normal.
\end{abstract}

Keywords Spheno-orbital $\cdot$ Meningioma $\cdot$ Surgery $\cdot$ Vision $\cdot$ Hyperostosis

This article is part of the Topical Collection on Tumor - Meningioma

Previous presentations Parts of the results described in this manuscript were presented at the 13th Congress of the European Skull Base Society in 2018 in Warsaw, Poland.

Electronic supplementary material The online version of this article (https://doi.org/10.1007/s00701-020-04554-9) contains supplementary material, which is available to authorized users.

Amir H. Zamanipoor Najafabadi amir@lumc.nl

1 University Neurosurgical Centre Holland, Leiden University Medical Centre, Haaglanden Medical Centre and Haga Teaching Hospital, Leiden and The Hague, The Netherlands

2 Department of Ophthalmology, Leiden University Medical Center, Leiden, The Netherlands

3 Orbital Center, Department of Ophthalmology, Amsterdam University Medical Center, Amsterdam, The Netherlands

\section{Introduction}

Spheno-orbital meningioma (SOM) are tumors originating from the sphenoid ridge, primarily characterized by hyperostosis of the lesser and/or greater sphenoid wing [22, 28]. In addition, the majority of patients have an intradural meningioma, often described as a thin "carpet-like" or "en-plaque" tumor, which can be more extensive including cavernous sinus involvement and an intraorbital component [21, 23, 28]. Due to its location, the majority of patients present with visual deficits and/or proptosis [30].

Due to the low incidence of SOM, current series in the literature describe smaller and larger patient series often covering multiple decades, while surgical techniques have improved over the years $[3,9,14-16,19,21-23,28,31]$. In these series, surgery has proven its value with improvement of visual function $(10-73 \%)$ and proptosis $(50-93 \%)$ [3, 9, 
$14-16,19,22,23,28]$. Nevertheless, many papers only describe the preoperative and postoperative visual acuity and proptosis, neglecting patients' visual fields deficits, while this is strongly associated with patients' health-related quality of life $[9,15,16,19,21,23]$. In addition, predictors of visual outcomes have not yet been systematically assessed. Identification of these predictors may optimize the decision and timing of surgical treatment and tailor postsurgical ophthalmological follow-up.

Therefore, we aimed to describe visual outcomes, complications and recurrence in a recent cohort of surgically treated SOM patients in a high-volume referral centre with a dedicated multidisciplinary team. In addition, we systematically assessed predictors of short- and longer-term postoperative best corrected visual acuity (BCVA), visual fields, and proptosis.

\section{Methods}

\section{Study setting and subject selection}

Consecutive (i.e., no case selection) spheno-orbital meningioma patients operated between June 2015 and January 2019 in the Leiden University Medical Center (LUMC) in Leiden the Netherlands were described in this study. A set team of a neurosurgeon (WRvF) and orbital/ oculoplastic surgeon (SWG) operated patients and followed patients at their multidisciplinary outpatient clinic. SOM was defined as an inner sphenoid-ridge meningioma with hyperostosis of at least the lesser or greater sphenoid wing with an intradurual meningioma. Patients were excluded if previously operated. In our center the usual first line treatment of SOM consists of surgery, with radiotherapy reserved for recurrent tumors. This study was reviewed and approved by the LUMC-LDD medical ethics committee as part of a larger study protocol (G19.011).

\section{Surgical technique}

The pterional approach was used in all cases. Patients were positioned in the supine position, with the head extended and rotated to the contralateral side. An interfascial temporal flap was developed to expose the skull [38]. Neuronavigation was used to verify extension of bony resection. Hyperostotic bone of the orbital roof and lateral orbital wall was microscopically decompressed from the maxillary strut to the optic strut using the eggshell technique, which comprises thinning of bone to softly peel the layer of bone around critical structures. If involved the optic canal was decompressed in total length. The meningo-orbital band was cut to fully expose the superior orbital fissure (Fig. 1). Intradural meningioma was removed, but no attempts were made to remove intracavernous sinus meningioma. Intraorbital meningioma was resected by the orbital surgeon, and periorbita was partially resected, or incised, to reduce proptosis. Common grafting techniques (cranial periosteum, donor, or artificial material) were used for watertight dural reconstruction. If indicated, the lateral orbital wall was reconstructed with titanium mesh, or patient-specific 3Dprinted PEEK (polyetheretherketone) implant to prevent pulsatile enopthalmos and/or adhesion of the temporal muscle to the periorbita. Abdominal fat or gelatine-based artificial material was used to fill-up the defect. The surgical technique was somewhat modified over time based on developing experiences and new insights.

\section{Data collection}

Demographic characteristics were collected from the electronic patient charts. Patients underwent both computed tomography (CT) and gadolinium contrast-enhanced magnetic resonance imaging (MRI) both before and after surgery (postoperative: after 6 months and then yearly). Multiple visual outcomes were measured preoperatively, and postoperatively at 3,6 , and 12 months, after which patients were seen yearly in the multidisciplinary outpatient clinic of both surgeons. Best corrected visual acuity (BCVA) was measured with the Snellen chart. Patient's visual fields were investigated using the Zeiss Humphrey visual field analyzer, described as mean deviation (MD) in decibel (dB). Proptosis was determined by measuring axial globe position using a double-prism exopthalmometer, comparing the affected eye with the unaffected eye [11].

\section{Statistical analysis}

Outcomes after surgery are described as the percentage of patients with deteriorated, stable, improved or normalized BCVA, visual fields, and proptosis. Preoperative outcomes were compared with direct postoperative outcomes using the Wilcoxon signed rank test. Individual patient data are graphically depicted over time for all outcomes in graphs. Furthermore, median values were calculated for all patients together and for those patients with and without preoperative visual acuity deficits (cut-off for deficit 0.8 or lower), visual field deficits (cut-off for deficit $-5 \mathrm{~dB}$ or lower) [26], or proptosis (cut-off for clinically relevant proptosis $2 \mathrm{~mm}$ or more). No cut-offs for improvement on the individual patient level were set, as clinical interpretation of improvement is highly dependent on the preoperative status (e.g., visual acuity improvement of 0.0 to 0.4 vs 1.0 to 1.4). Instead, the above-mentioned cut-offs were used both preoperatively and postoperatively and 
Fig. 1 Example of spheno-orbital meningioma patient management. (A) Patient presented with a relative proptosis of $8 \mathrm{~mm}$ of the right eye, BCVA of 0.6 , and a visual field deficit of $-6.50 \mathrm{~dB}$. (B) Hyperostosis of both the orbital roof and lateral orbital wall is shown on the CT scan in bone setting. (C/D) Pictures of the microsurgical decompression. MOB meningo-orbital band, OR orbital roof, LOW lateral orbital wall, MS maxillary strut, MN maxillary nerve. (E) A Simpson grade I resection was achieved after intradural and intraorbital meningioma resection. (F) After resection of intraorbital meningioma, vertical cuts were made in the periorbita to reduce proposes. (G) Postoperative facial picture showed clear reduction of proptosis. Her BCVA normalized (1.20) as well as the visual field deficit $(-0.33 \mathrm{~dB})$. (H) CT scan in bone setting showed reduction of hyperostotic bone and reconstruction of the lateral orbital wall with titanium mesh.

Figures published with permission of the patient after written informed consent

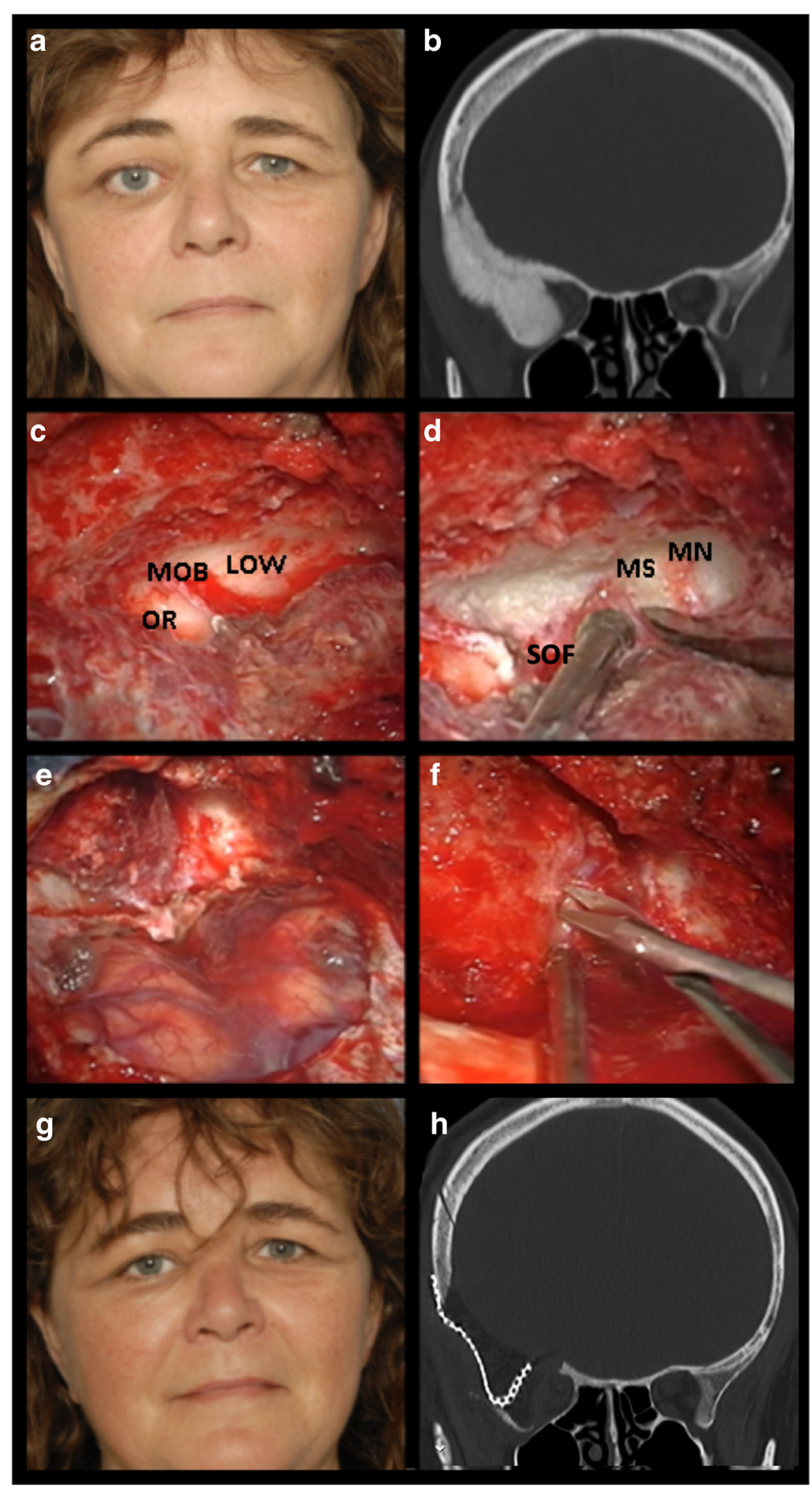

distinction was made between postoperative improvement and normalization of visual outcomes. Predictors of BCVA, visual fields and proptosis were assessed by univariable linear regression analysis, separately for the direct postoperative outcomes (3 months) and outcomes at longest follow-up. No multivariable analysis was performed due to the small number of patients. IBM SPSS Statistics version 23.0 (Armonk, NY, USA) was used for all statistics, and a $p<0.05$ was considered statistically significant. 


\section{Results}

\section{Subjects}

During the study period, 20 patients were operated, but one patient was lost to follow-up, as the patient died due to comorbidities not related to the SOM or surgery. The remaining 19 patients were described in this study (median age: 47.0, 97\% female). All patients suffered from unilateral disease. See Table 1 for a description of all baseline characteristics. Median follow-up time between diagnosis and surgery was 7.2 months, as a short wait-and scan regimen was chosen as

Table 1 Baseline characteristics of Spheno-orbital meningioma patients

\begin{tabular}{|c|c|}
\hline & $\begin{array}{l}\text { LUMC cohort } \\
(n=19)\end{array}$ \\
\hline Gender, female & $18(95 \%)$ \\
\hline Age at surgery, years & $47.0(45.0-50.0)$ \\
\hline Time between diagnosis and surgery in months & $7.2(3.4-8.9)$ \\
\hline Hyperostosis diameter (mm) & $31.0(24.0-35.0)$ \\
\hline Soft tissue diameter (mm) & $11.0(8.0-18.0)$ \\
\hline \multicolumn{2}{|l|}{ Simpson grade } \\
\hline Grade I & $6(32 \%)$ \\
\hline Grade II & $9(47 \%)$ \\
\hline Grade III & $0(0 \%)$ \\
\hline Grade IV & $4(21 \%)$ \\
\hline \multicolumn{2}{|l|}{ Extent of resection } \\
\hline Full resection & $15(79 \%)$ \\
\hline Subtotal resection & $4(21 \%)$ \\
\hline WHO grade I & $19(100 \%)$ \\
\hline \multicolumn{2}{|l|}{ WHO subtypes } \\
\hline Meningothelial & $15(79 \%)$ \\
\hline Transitional & $3(16 \%)$ \\
\hline Secretory & $1(5 \%)$ \\
\hline \multicolumn{2}{|l|}{ Number of tumors } \\
\hline 1 & $13(69 \%)$ \\
\hline 2 & $3(16 \%)$ \\
\hline 3 & $0(0 \%)$ \\
\hline 4 & $1(5 \%)$ \\
\hline 5 & $2(11 \%)$ \\
\hline Postoperative proton radiotherapy & $2(11 \%)$ \\
\hline Postoperative photon radiotherapy & $1(5 \%)$ \\
\hline Reoperation & $2(11 \%)$ \\
\hline Follow-up length in years & $2.4(1.3-3.3)$ \\
\hline
\end{tabular}

Continuous outcomes are described as median value and interquartile range. Dichotomous outcomes are described as number and percentages. Percentages might not add up to $100 \%$ due to rounding

Extent of resection was determined intraoperatively and on postoperative CT and MRI scan. A subtotal resection was defined as residual meningioma tissue or hyperostosis initial treatment for patients who only presented with proptosis without any visual deficits. Median follow-up time after surgery was 2.4 years (IQR 1.3 to 3.3 ).

\section{Surgical techniques}

In all cases the pterional approach was used, including decompression of the lateral orbital wall and superiorior orbital fissure (Table 2). The principles of the used surgical technique modified somewhat over time; the meningo-orbital band was cut in the last 10 patients (38\%) to facilitate full exposure of the superior orbital fissure. Furthermore, in the first couple of operated patients the optic canal and orbital roof were only decompressed if preoperative CT showed extensive hyperostosis of these structures and/or a patient presented with visual acuity or visual field deficits. In the last 12 patients the orbital roof and optic canal were decompressed in all patients.

Table 2 Surgical techniques

\begin{tabular}{|c|c|}
\hline & $\begin{array}{l}\text { LUMC cohort } \\
(n=19)\end{array}$ \\
\hline \multicolumn{2}{|l|}{ Resection hyperostotic bone } \\
\hline Lateral orbital wall & $19(100 \%)$ \\
\hline \multicolumn{2}{|l|}{ Orbital roof } \\
\hline Complete & $10(53 \%)$ \\
\hline Partial & $5(26 \%)$ \\
\hline Not & $4(21 \%)$ \\
\hline Anterior clinoid process & $1(5 \%)$ \\
\hline \multicolumn{2}{|l|}{ Decompression of foramina } \\
\hline Superior orbital fissure & $19(100 \%)$ \\
\hline \multicolumn{2}{|l|}{ Optic canal } \\
\hline Complete (full-length) & $7(37 \%)$ \\
\hline Partial & $5(26 \%)$ \\
\hline Not & $7(37 \%)$ \\
\hline Foramen rotundum & $1(5 \%)$ \\
\hline Foramen ovale & $0(0 \%)$ \\
\hline Foramen spinosum & $1(5 \%)$ \\
\hline \multicolumn{2}{|l|}{ Resection of soft-tissue structures } \\
\hline Meningo-orbital band & $10(53 \%)$ \\
\hline Intraorbital meningioma & $10(53 \%)$ \\
\hline \multicolumn{2}{|l|}{ Periorbita management } \\
\hline Cuts & $4(22 \%)$ \\
\hline Stripping & $7(37 \%)$ \\
\hline Nothing & $8(42 \%)$ \\
\hline \multicolumn{2}{|l|}{ Reconstruction } \\
\hline Patient-specific 3D PEEK implant & $3(16 \%)$ \\
\hline Titanium mesh reconstruction & $12(63 \%)$ \\
\hline No reconstruction performed & $4(21 \%)$ \\
\hline Periumbilical fat filling & $11(58 \%)$ \\
\hline
\end{tabular}

Percentages might not add up to $100 \%$ due to rounding PEEK polyetheretherketone 
Resection of the anterior clinoid process and decompression of the foramen rotundum, ovale, and spinosum were only performed when clinically indicated. In the first patients, reconstruction of the lateral orbital wall was performed with titanium mesh, while in recent patients patient-specific 3Dprinted PEEK implants were used for reconstruction. Gross total resection, i.e., resection of meningioma tissue and hyperostotic bone, was achieved in 14 patients (74\%). A subtotal resection was achieved in $5(26 \%)$ patients, due to extensive hyperostosis over the skull base.

\section{Visual outcomes}

Ten $(53 \%)$ patients suffered from a decrease in BCVA, which normalized in $7(70 \%)$ after surgery, improved in $1(10 \%)$, and remained unchanged in $2(20 \%$, preoperative BCVA: 0.0 and 0.7 ) patients. Median BCVA before surgery was 0.8 (IQR 0.7 to 1.5 ), which improved postoperatively to 1.2 (IQR 1.0 to $1.5, p=0.021)$, and remained stable in all patients at 1-year follow-up (1.2, IQR 1.0 to 1.5) and longer follow-up (1.2, IQR 1.0 to 1.5 ). Eight (42\%) patients had preoperative visual field deficits, which normalized in all (100\%) patients after surgery. Median visual field before surgery was $-6.5 \mathrm{~dB}$ (IQR -12.9 to -3.0 ), which improved postoperatively to $-1.5 \mathrm{~dB}$ (IQR 2.2 to $-0.7, p=0.03)$ and remained stable in seven $(88 \%)$ patients at 1-year follow-up (all patients $-1.7 \mathrm{~dB}, \mathrm{IQR}-2.5$ to -1.1 ) and longer follow-up (all patients $-1.3 \mathrm{~dB}, \mathrm{IQR}-$ 3.2 to -0.3$)$. One patient suffered from a strong deterioration $(-23.1 \mathrm{~dB})$ after 1-year follow-up. Sixteen $(84 \%)$ patients presented with proptosis preoperatively, which normalized in seven (44\%) and improved in nine (54\%) patients. Median relative proptosis before surgery was $5 \mathrm{~mm}$ (IQR: 3.0 to 6.5 ), which improved postoperatively to $2 \mathrm{~mm}$ (IQR: 1.0 to $3.3, p<0.01)$. However, four of these patients $(25 \%)$ suffered from deterioration at 1-year follow-up (all patients $3 \mathrm{~mm}$, IQR 2 to 4 ) and one patient (6\%) at longer follow-up (all patients $4 \mathrm{~mm}, \mathrm{IQR} 2$ to 5). Individual patient data over time of BCVA, visual fields, and proptosis are depicted in Fig. 2. In addition, median values are provided for all patients together and separately for patients with and without preoperative visual acuity deficits, visual field deficits, and proptosis.

\section{Complications and reintervention}

Patients suffered from the following postoperative complications: transient $(n=3)$ and permanent $(n=3)$ hypesthesia of the maxillary nerve, transient deficit of the frontal branch of the facial nerve with consequently asymmetry of the eyebrows ( $n=3$ ), wound abscess requiring debridement of the wound $(n=1)$, preseptal orbital cellulitis $(n=1)$ which was successfully treated with antibiotics, and oscillopsia during chewing $(n=1)$ for which eventually a patient-specific 3D-printed
PEEK reconstruction was performed. No complications of the other cranial nerves or surgical mortality were observed. After 1-year follow-up two patients developed MRI established growth of residual tumor, for which one patient received photon radiotherapy 1.5 years after surgery and one patient received proton beam therapy 4.0 years after surgery. As stated before, one patient suffered from strong deterioration of visual fields $(-23.1 \mathrm{~dB})$, requiring reresection and proton beam therapy, which improved and stabilized the patient's visual field deficit $(-10.0 \mathrm{~dB})$. One patient required reresection for the development of ophthalmoplegia, which improved the patient's symptoms. In these four patients the optic canal was decompressed in one and the orbital roof in three patients.

\section{Predictors of short- and longer-term postoperative visual acuity, visual fields, and proptosis}

Short-term Predictor for worse short-term postoperative BCVA was worse preoperative BCVA: for each point lower preoperative BCVA, postoperative BCVA was 0.49 lower ( $95 \% \mathrm{CI}-0.21$ to $-0.77, p=0.002$ ). No predictors were identified for short-term visual fields. Predictor of worse postoperative proptosis was worse preoperative proptosis: for each additional millimeter preoperative proptosis, postoperative proptosis was $0.47 \mathrm{~mm}$ higher $(95 \%$ CI 0.16 to $0.78, p=$ $0.006)$. Detailed information about predictors of short-term outcomes is provided in Supplementary Table 1.

Longer-term Predictors for worse longer-term BCVA were worse preoperative $\operatorname{BCVA}(\beta=-0.49,95 \% \mathrm{CI}-0.21$ to $0.77, p=0.002$ ), and the number of tumors, as for each extra diagnosed meningioma postoperative BCVA was -0.14 lower $(95 \% \mathrm{CI}-0.26$ to $-0.02, p=0.021)$. Predictors for worse postoperative visual fields were the maximum diameter of preoperative hyperostosis: for each additional millimeter preoperative hyperostosis, postoperative visual fields were $0.39 \mathrm{~dB}$ lower (95\%CI -0.67 to $-0.12, p=0.009$ ), and Simpson grade: for each grade increase in Simpson grade, postoperative visual fields were $3.71 \mathrm{~dB}$ lower $(95 \% \mathrm{CI}-6.63$ to $-0.78, p=$ $0.017)$. No predictors were identified for longer-term proptosis. Detailed information about predictors of longer-term outcomes is provided in Supplementary Table 2.

\section{Discussion}

In a recent cohort of spheno-orbital meningioma patients operated by a dedicated team of a neurosurgeon and orbital surgeon in a high-volume referral center good visual outcomes were achieved and maintained with modest morbidity and no mortality. Postoperative visual acuity and visual fields endorsed surgery of patients with SOM, even with minimal visual 
Individual patient data
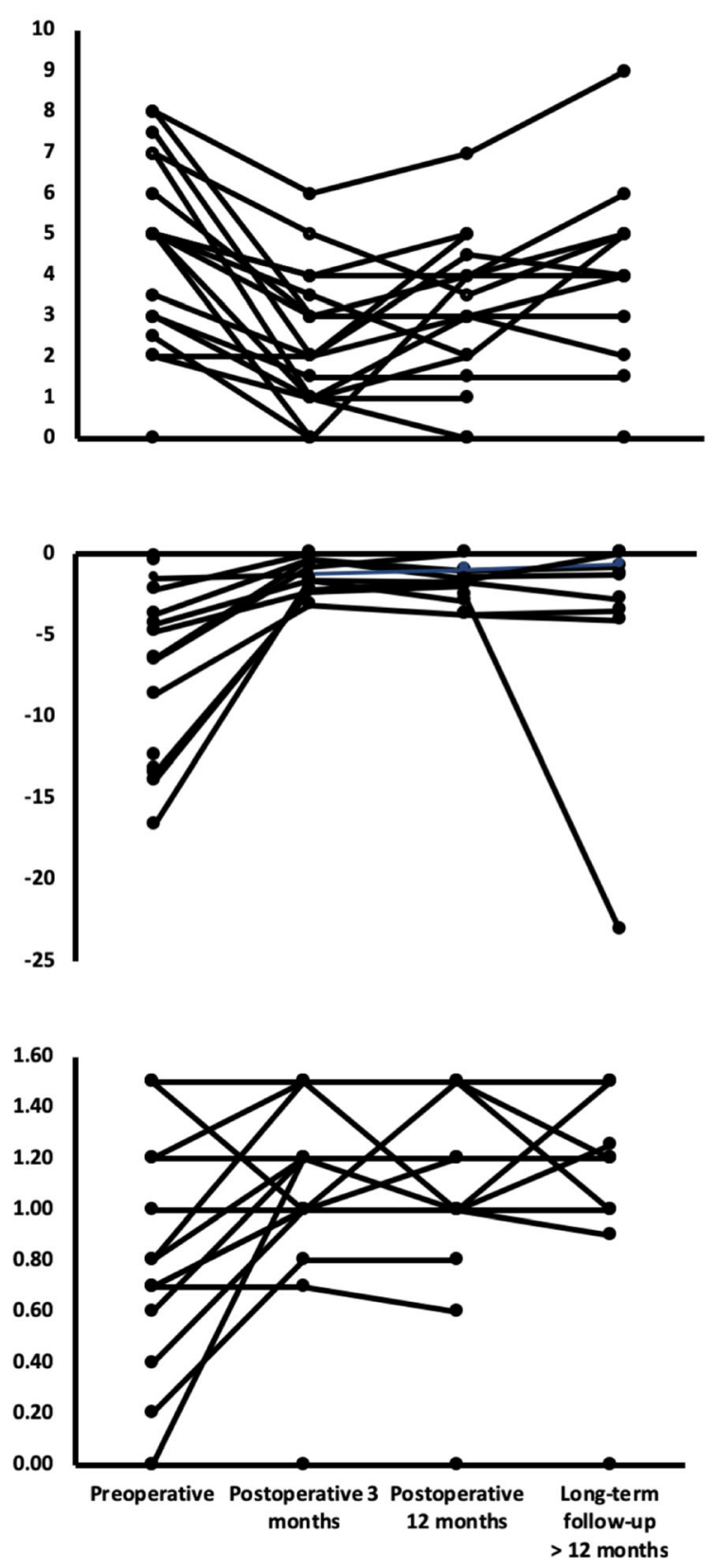

Fig. 2 Preoperative and postoperative measures of proptosis, visual fields, and visual acuity are depicted for individual patients and grouped for all patients and patients with and without preoperative deficits. Proptosis was measured with a Hertel exopthalmometer in $\mathrm{mm}$. Visual

impairment or hyperostosis, as we showed with our regression analysis that preoperative visual deficits and the maximum diameter of hyperostosis were predictors of poorer outcome.

Results of this mono-center study were in line with published studies of the last two decades, which reported improvement of vision in $37-87 \%$ of patients, visual fields in $17-88 \%$, proptosis in $60-100 \%$, and permanent complications in $22-44 \%$ of patients $[6,14,16,28$, 34-36]. We reported improvement of visual acuity in
Grouped for preopreative status
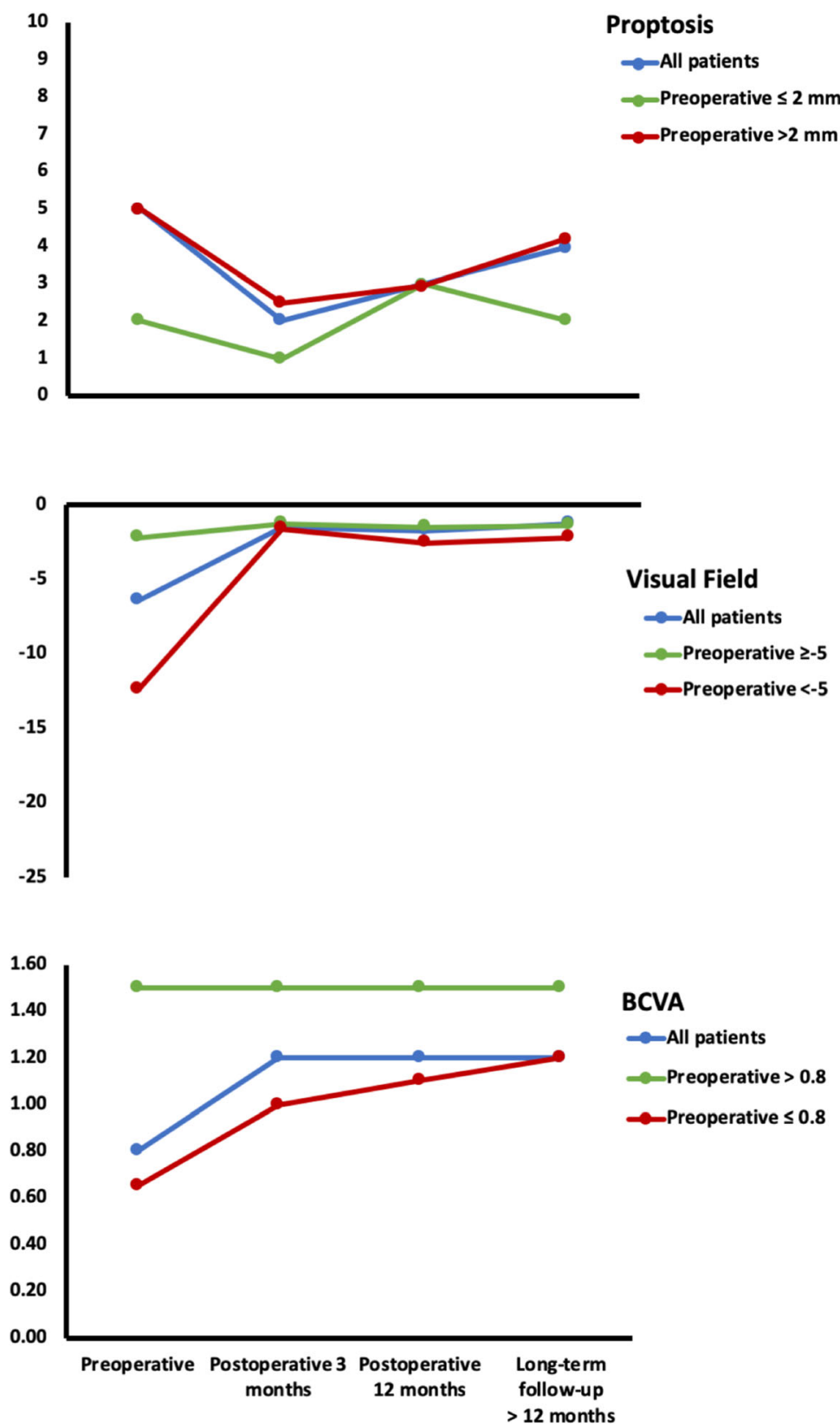

fields were measured with the Humphrey visual field analyzer, described as mean deviation (MD) in decibel (dB). Visual acuity was measured with the Snellen chart

$80 \%$ and visual fields in $100 \%$ of patients with stable outcomes in $95 \%$ of these patients during our modest follow-up period. Proptosis was also improved in all patients; however, $21 \%$ reported deterioration at longer follow-up. We observed permanent complications in $32 \%$. Despite the good visual outcomes, $21 \%$ of patients showed progression requiring reresection, which was comparable to the outcomes $(22-48 \%)$ of recently published studies by other groups $[6,9,25,36]$. 


\section{Predictors of postoperative vision}

Based on our results, multiple data-driven recommendations can be made to optimize surgery and postsurgical follow-up for SOM patients (Table 3). Our results suggest that it might be beneficial to operate patients, even with minimal visual impairment or hyperostosis, to prevent the development of visual deficits, that might not completely resolve after surgery (i.e., strongest predictors for postoperative visual outcomes were preoperative visual function and hyperostosis), which is in line with conclusions reported in published literature [9, 16, 19, 21, 23, 34, 36, 37]. Our, relatively short, follow-up results suggest early surgery has a lasting change on the clinical course of the disease, with persisting good visual outcomes in the majority of patients. Patients with normal visual function, operated for their proptosis, maintained good visual outcomes after surgery. While surgery of patients with minimal visual symptoms seems intuitive and was recommended by other case series, these studies did not systematically assess predictors of postoperative visual outcomes $[9,16,19,21,23,34,36,37]$. As these tumors tend to invade the bone near the foramina of the cranial nerves, early surgery might prevent extensive hyperostosis, narrowing of formina, and consequently cranial nerve deficits $[16,22]$. Indeed, it is reported that optic canal and intraorbital involvement are predictors for postoperative visual deficits [37]. Nevertheless, we also acknowledge that surgery itself imposes a risk of new visual and cranial nerve deficits $[6,28]$. Especially in very old patients, patients with severe comorbidities, or patients with extensive disease resulting in full blindness, the benefits of surgery might not always outweigh the risk of complications. However, in general, we believe that the risk for new complications might be smaller when patients are operated on early in their disease course, as cranial nerves are less vulnerable when compression is less severe. Our results also indicate that patients diagnosed with multiple intracranial meningioma were at higher risk for postoperative visual acuity deficits. Therefore, we advise a more intensive multidisciplinary postsurgical follow-up for these patients to identify objective or subjective postoperative visual deterioration as early as possible, enabling early reresection. The need for repeat intervention was high in this group.

\section{Surgical approaches}

Although multiple surgical approaches have been described for SOM surgery, the pterional approach is the most used approach in these patients, and also used for all patients described in this study $[15,16,19,24,28,35]$. Advantages of pterional craniotomy are wide exposure and access to the anterior, middle, and temporal cranial fossa, and therefore ability to resect the hyperostotic bone and soft-tissue tumor as radically as possible. Recently, multiple endoscopic approaches have been described for anterior skull base pathology, such as the supraorbital, and the combined endonasal and transorbital approach $[5,7,13,17,18$, 27, 41]. Three studies described a total of 12 SOM patients operated with the endonasal transorbital approach $[1,5,18]$.

Table 3 Recommendations for surgical indication, surgical technique and patient follow-up

\begin{tabular}{|c|c|c|c|}
\hline Current practice & Recommendations & Evidence current study & $\begin{array}{l}\text { Literature supporting } \\
\text { recommendation }\end{array}$ \\
\hline \multicolumn{4}{|l|}{ Indication for surgery } \\
\hline $\begin{array}{l}\text { - Significant visual symptoms or } \\
\text { proptosis }\end{array}$ & $\begin{array}{l}\text { - Prevention of visual deficits by } \\
\text { early surgery, even of patients } \\
\text { with minimal visual impairment } \\
\text { or hyperostosis }\end{array}$ & $\begin{array}{l}\text { - Worse preoperative deficits } \\
\text { were related to worse } \\
\text { postoperative outcomes }\end{array}$ & $\begin{array}{l}\cdot[9,16,19,21,23,34 \\
\quad 36,37 \\
\quad]\end{array}$ \\
\hline \multicolumn{4}{|l|}{ Surgical technique } \\
\hline $\begin{array}{l}\text { - Resection of hyperostotic bone } \\
\text {-Limited resection of intraorbital } \\
\text { meningioma and periorbita } \\
\text { - Reconstruction in some patients }\end{array}$ & $\begin{array}{l}\text { - Maximum resection of } \\
\text { hyperostotic bone: at least the } \\
\text { lateral orbital wall, orbital roof, } \\
\text { optic canal, and superior orbital } \\
\text { fissure } \\
\text { - Maximum intraorbital meningioma } \\
\text { resection, including periorbita } \\
\text { - Reconstruction with titanium } \\
\text { mesh or customized 3d-printed } \\
\text { PEEK implant }\end{array}$ & $\begin{array}{l}\text { - Need for reresection or } \\
\text { radiotherapy was observed in } \\
\text { patients without } \\
\text { decompression of orbital roof } \\
\text { and optic canal } \\
\text { - Simpson grade was predictive } \\
\text { for long-term visual } \\
\text { field deficits } \\
\text { - Reconstruction with titanium } \\
\text { mesh or 3D-printed PEEK im- } \\
\text { plant showed good postopera- } \\
\text { tive proptosis results }\end{array}$ & $\begin{array}{l}\cdot[6,19,28,34] \\
\cdot[12,19,20,25,32,36] \\
\cdot[2,6,8,14,19,34,36]\end{array}$ \\
\hline \multicolumn{4}{|l|}{ Patient follow-up } \\
\hline - Routine meningioma follow-up & $\begin{array}{l}\text { - More frequent follow-up } \\
\text { of patients with multiple menin- } \\
\text { gioma }\end{array}$ & $\begin{array}{l}\text { - Tumor number was predictive } \\
\text { for long-term visual acuity }\end{array}$ & - No relevant literature \\
\hline
\end{tabular}


The endonsasal approach was used for decompression of the medial part of the optic canal. Further decompression of the hyperostotic bone and tumor removal was accomplished with the transorbital approach $[1,5,18]$. Compared with endonasal approach only, this combined approach enabled resection of more laterally located pathology [5]. Overall these case series showed stabilization of visual function with moderate to good reduction of proptosis. Proposed advantages are the less invasive approach with cosmetically pleasing results. However, gross total resection is often not possible, and therefore, these approaches should be preserved for selected patients with suspected benign meningioma with minimal intradural growth and in whom relief of symptoms through decompression of the optic canal is the primary goal [1]. In these cases residual tumor can be controlled by radiotherapy [1].

\section{Hyperostotic bone resection, dealing with the periorbita, and reconstruction techniques}

In the last decades a paradigm shift has occurred in skull base surgery from aiming maximum surgical resection to optimizing patient outcomes and health-related quality of life [39, 40]. A maximum resection of hyperostotic bone is advocated to reduce proptosis, to restore visual function, and to minimize progression. However, there is no consensus on the degree of bony resection, the need to resect invaded periorbit, and the need for reconstruction of the lateral orbital wall. We agree with earlier reports that cavernous sinus involvement is a contra-indication for gross-total resection $[16,22,24,36]$. Some of the same reports advise no decompression of superior orbital fissure tumor involvement. However, with transection of the meningo-orbital band, full decompression of the superior orbital fissure is possible [10]. It remains controversial whether resection of bone should be limited to clearly visible hyperostotic bone or whether decompression of the optic canal and possible other foramina should be performed routinely for preservation of good visual function [36]. We recommend resection of at least the orbital roof and lateral orbital wall, and decompression of the optic canal, and superior orbital fissure to prevent further deterioration of visual outcomes and improve proptosis (Table 3). Although standard resection of the anterior clinoid process is performed by others, we only advise to resect this structure in case of hyperostosis to prevent early postoperative progression, as no cranial nerves are directly affected by hyperostosis of the anterior clinoid process $[2,19,22$, $23,28,36]$. Another debate is the need for resection of the periorbit. While this should clearly be done when the periorbit is invaded with tumor, it is advocated by some to preserve the periorbit to prevent pulsatile enopthalmos. However, we agree with others that resection of the periorbit is critical to maximally reduce proptosis. Based on our own experience and the reported literature, we advise reconstruction with titanium mesh or customized patient-specific 3D PEEK implants to prevent (pulsatile) enopthalmos, especially in case of periorbit resection $[2,14-16$,
$19,23,31,36]$. Other groups have reported to actually not perform reconstruction to provide an even greater reduction of proptosis $[22,28,35]$.

\section{Progression and adjuvant treatment}

In this case series with limited follow-up length, $21 \%$ of patients needed reintervention. Two patients showed established tumor growth without the development of new visual deficits. These patients were treated with radiotherapy to halt the tumor growth. While radiotherapy is associated with optic neuropathy, extraocular muscle dysfunction, and pituitary insufficiency [6, 25], irradiation was chosen over reoperation, as the growing tumor remnants were deemed difficult to fully resect. Especially with the introduction of proton beam therapy, irradiation might be less harmful than reoperation for cases with residual disease or tumor regrowth without symptoms of newly developed visual deficits [4]. However, in the two patients with newly developed visual deficits due to postoperative tumor growth, reoperation was chosen in an attempt to decompress the optic system to improve the visual function of the patient. These percentages and treatment strategies for recurrent disease are in line with other case series [2, $6,28,33]$. Although our case series did not include any patients with a WHO grade II tumor, other authors advise upfront radiotherapy for these patients $[6,29]$.

\section{Strengths and limitations}

Strengths of this study are the use of a recent cohort of SOM patients operated by a dedicated set team of a neurosurgeon and orbitoplastic surgeon for assessment of short- and longer-term visual outcomes. Furthermore, we prospectively comprehensively assessed visual outcomes not only reporting visual acuity but also standardized measurement of visual fields. Only few studies have been published reporting results of visual fields, while this is a significant symptom for patients, highly correlated with their health-related quality of life [26]. Another strength is the assessment of predictors for postoperative visual outcomes, enabling formulation of recommendations for SOM surgery and patient follow-up. However, due to the small number of patients no multivariable analysis was performed, and ideally, our results should be validated in a larger (international) dataset to ensure robustness of the results. Although we did not perform a direct comparison between patients with an early vs. late stage disease, we formulated that surgery of patients with minimal visual impairment or hyperostosis might provide better postoperative results, as predictors of worse postoperative visual outcomes were worse preoperative visual acuity and a larger diameter of proptosis. While more intuitive, a direct comparison of early vs. later surgery was not possible due to the small patient sample and might actually not be preferred, as it does not take into account the extent of disease and visual status at diagnosis. Longer 
follow-up is needed to assess more accurate recurrence rates and the long-term outcomes after reresection and radiotherapy.

\section{Conclusions}

The aim of surgery for spheno-orbital meningioma should be to optimize visual outcomes and health-related quality of life. As spheno-orbital meningioma is a rare disease with significant treatment variation, sound comparison of different treatment strategies and outcomes can only be performed through international collaboration and harmonized data collection. In lack of that, we present outcome data of our recent small series and make an argument for surgical intervention of spheno-orbital meningiomas, even in patients with limited visual impairments or hyperostosis, as worse preoperative visual acuity, and greater diameter of hyperostosis were predictors of poorer visual outcome.

Authors' contribution AHZN, SWG, and WRvF designed the study and collected data. AHZN performed data analysis and wrote the first and successive versions of the manuscript. All authors contributed to the interpretation of the results, intellectual content, critical revisions to the drafts of the paper, and approved the final version. AHZN had full access to all the data in the study and had final responsibility for the decision to submit for publication.

Funding The Leiden University Medical Center provided financial support in the form of a personal $\mathrm{MD} / \mathrm{PhD}$ grant funding for AHZN. The sponsor had no role in the design or conduct of this research.

\section{Compliance with ethical standards}

Conflict of interest All authors certify that they have no affiliations with or involvement in any organization or entity with any financial interest (such as honoraria; educational grants; participation in speakers' bureaus; membership, employment, consultancies, stock ownership, or other equity interest; and expert testimony or patent-licensing arrangements), or non-financial interest (such as personal or professional relationships, affiliations, knowledge, or beliefs) in the subject matter or materials discussed in this manuscript.

Ethical approval All procedures performed in studies involving human participants were in accordance with the ethical standards of the institutional and/or national research committee (name of institute/committee) and with the 1964 Helsinki declaration and its later amendments or comparable ethical standards. This cross-sectional study was approved by the medical ethical committees of the Leiden University Medical Center as part of a larger study protocol (G19.011).

Informed consent Informed consent was obtained from all individual participants included in the study. Additional informed consent was obtained from all individual participants for whom identifying information is included in this article.

Open Access This article is licensed under a Creative Commons Attribution 4.0 International License, which permits use, sharing, adaptation, distribution and reproduction in any medium or format, as long as you give appropriate credit to the original author(s) and the source, provide a link to the Creative Commons licence, and indicate if changes were made. The images or other third party material in this article are included in the article's Creative Commons licence, unless indicated otherwise in a credit line to the material. If material is not included in the article's Creative Commons licence and your intended use is not permitted by statutory regulation or exceeds the permitted use, you will need to obtain permission directly from the copyright holder. To view a copy of this licence, visit http://creativecommons.org/licenses/by/4.0/.

\section{References}

1. Almeida JP, Omay SB, Shetty SR, Chen Y, Ruiz-treviño AS, Liang B, Anand VK, Levine B, Schwartz TH (2017) Transorbital endoscopic eyelid approach for resection of sphenoorbital meningiomas with predominant hyperostosis: report of 2 cases. J Neurosurg 28(6). https://doi.org/10.3171/2017.3.JNS163110

2. Boari N, Gagliardi F, Spina A, Bailo M, Franzin A (2017) Mortini P (2013) management of spheno-orbital en plaque meningiomas: clinical outcome in a consecutive series of 40 patients. Br J Neurosurg 27:84-90

3. Cannon PS, Rutherford SA, Richardson PL, King A, Leatherbarrow B (2009) The surgical management and outcomes for spheno-orbital meningiomas: a 7-year review of multidisciplinary practice. Orbit 28(6):371-376

4. Combs SE, Ganswindt U, Foote RL, Kondziolka D, Tonn JC (2012) State-of-the-art treatment alternatives for base of skull meningiomas: complementing and controversial indications for neurosurgery, stereotactic and robotic based radiosurgery or modern fractionated radiation techniques. Radiat Oncol 7(1):1-9

5. Dallan I, Castelnuovo P, Locatelli D, Turri-Zanoni M, AlQahtani A, Battaglia P, Hirt B, Sellari-Franceschini S (2015) Multiportal combined transorbital transnasal endoscopic approach for the management of selected skull base lesions: preliminary experience. World Neurosurg:1-11

6. Dalle Ore CL, Magill ST, Rodriguez Rubio R et al (2020) Hyperostosing sphenoid wing meningiomas: surgical outcomes and strategy for bone resection and multidisciplinary orbital reconstruction. J Neurosurg:1-10

7. De JR, Vescan AD, Gullane PJ, Gentili F, Lee JM, Lohfeld L, Ringash J, Thoma A, Witterick IJ (2012) Development of a disease-specific quality-of-life questionnaire for anterior and central skull base pathology - the skull base inventory. Laryngoscope 122(9):1933-1942

8. Essa AA, Hamdan AR (2018) Sphenoid meningioma enplaque with proptosis: surgical excision, reconstruction and outcome. Clin Neurol Neurosurg 167:147-156

9. Freeman JL, Davern MS, Oushy S, Sillau S, Ormond DR, Youssef AS, Lillehei KO (2017) Spheno-orbital meningiomas: a 16-year surgical experience. World Neurosurg 99:369-380

10. Fukuda H, Evins AI, Burrell JC, Iwasaki K, Stieg PE, Bernardo A (2014) The meningo-orbital band: microsurgical anatomy and surgical detachment of the membranous structures through a frontotemporal craniotomy with removal of the anterior clinoid process. J Neurol Surgery Part B Skull Base 75(2):125-132

11. Genders SW, Mourits DL, Jasem M, Kloos RJHM, Saeed P, Mourits MP (2015) Parallax-free exophthalmometry: a comprehensive review of the literature on clinical exophthalmometry and the introduction of the first parallax-free Exophthalmometer. Orbit 34(1):23-29

12. Gonen L, Nov E, Shimony N, Shofty B, Margalit N (2018) Sphenoorbital meningioma: surgical series and design of an intraoperative management algorithm. Neurosurg Rev 41(1):291-301

13. He H, Li W, Liang C, Luo L, Hou B, Yang H, Guo Y (2018) Eyebrow incision for combination supraorbital minicraniotomy 
with orbital osteotomy: application to cranio-orbital lesions. World Neurosurg. https://doi.org/10.1016/j.wneu.2018.03.043

14. Heufelder MJ, Sterker I, Trantakis C, Schneider JP, Meixensberger J, Hemprich A, Frerich B (2009) Reconstructive and ophthalmologic outcomes following resection of spheno-orbital meningiomas. Ophthal Plast Reconstr Surg 25(3):223-226

15. Honig S, Trantakis C, Frerich B, Sterker I, Meixensberger J, Honig S, Trantakis C, Frerich B, Sterker I, Schober R (2013) Sphenoorbital meningiomas : outcome after microsurgical treatment: a clinical review of 30 cases Spheno-orbital meningiomas : outcome after microsurgical treatment: a clinical review of 30 cases. Neurol Res A 6412(2017):314-325

16. Leroy HA, Leroy-Ciocanea CI, Baroncini M, Bourgeois P, Pellerin P, Labreuche J, Duhamel A, Lejeune JP (2016) Internal and external spheno-orbital meningioma varieties: different outcomes and prognoses. Acta Neurochir 158(8):1587-1596

17. Locatelli D, Pozzi F, Turri-zanoni M, Battaglia P, Santi L, Dallan I, Castelnuovo P (2016) Transorbital endoscopic approaches to the skull base: current concepts and future perspective. J Neurosurg Sci 60(December):514-528

18. Lubbe D, Mustak H, Taylor A, Fagan J (2016) Minimally invasive endo-orbital approach to sphenoid wing meningiomas improves visual outcomes - our experience with the first seven cases. Clin Otolaryngol:1-5

19. Marcus H, Schwindack C, Santarius T, Mannion R, Kirollos R (2013) Image-guided resection of spheno-orbital skull-base meningiomas with predominant intraosseous component. Acta Neurochir 155(6):981-988

20. Mariniello G, Maiuri F, Strianese D, Donzelli R, Iuliano A, Tranfa F, de Divitiis E, Bonavolontà G (2008) Spheno-orbital meningiomas: surgical approaches and outcome according to the intraorbital tumor extent. Zentralbl Neurochir 69(4):175-181

21. Mariniello G, Bonavolontà G, Tranfa F, Maiuri F (2013) Management of the optic canal invasion and visual outcome in spheno-orbital meningiomas. Clin Neurol Neurosurg 115(9): $1615-1620$

22. Maroon JC, Kennerdell JS, Vidovich DV, Abla A, Sternau L (1994) Recurrent spheno-orbital meningioma. J Neurosurg 80(2): 202-208

23. Mirone G, Chibbaro S, Schiabello L, Tola S, George B (2009) En plaque sphenoid wing meningiomas: recurrence factors and surgical strategy in a series of 71 patients. Neurosurgery 65(6 SUPPL. 1):100-109

24. Mortini P, Gagliardi F, Boari N, Losa M (2013) Surgical strategies and modern therapeutic options in the treatment of craniopharyngiomas. Crit Rev Oncol Hematol 88(3):514-529

25. Nagahama A, Goto T, Nagm A et al (2019) Spheno-orbital meningioma: surgical outcomes and management of recurrence. World Neurosurg 126:e679-e687

26. Patino CM, Varma R, Azen SP, Conti DV, Nichol MB, McKeanCowdin R (2011) The impact of change in visual field on healthrelated quality of life: the Los Angeles Latino Eye Study. Ophthalmology 118(7):1310-1317

27. Raza SM, Garzon-Muvdi T, Boaehene K, Olivi A, Gallia G, Lim M, Subramanian P, Quinones-Hinojosa A (2010) The supraorbital craniotomy for access to the skull base and intraaxial lesions: a technique in evolution. Minim Invasive Neurosurg 53(1):1-8

28. Ringel F, Cedzich C, Schramm J (2007) Microsurgical technique and results of a series of 63 spheno-orbital meningiomas. Neurosurgery 60(4 SUPPL. 2):214-222

29. Rogers L, Barani I, Chamberlain M, Kaley TJ, McDermott M, Raizer J, Schiff D, Weber DC, Wen PY, Vogelbaum MA (2015) Meningiomas: knowledge base, treatment outcomes, and uncertainties. A RANO review. J Neurosurg 122(1):4-23

30. Saeed P, Van Furth WR, Tanck M et al (2011) Natural history of spheno-orbital meningiomas. Acta Neurochir 153(2):395-401

31. Sandalcioglu IE, Gasser T, Mohr C, Stolke D, Wiedemayer H (2005) Spheno-orbital meningiomas: interdisciplinary surgical approach, resectability and long-term results. J Craniomaxillofac Surg 33(1010-5182 (Print)):260-266

32. Scarone P, Leclerq D, Héran F, Robert G (2009) Long-term results with exophthalmos in a surgical series of 30 sphenoorbital meningiomas: clinical article. J Neurosurg 111(5):1069-1077

33. Shapey J, Jung J, Barkas K, Gullan R, Barazi S, Bentley R, Huppa C, Thomas NW (2019) A single centre's experience of managing spheno-orbital meningiomas: lessons for recurrent tumour surgery. Acta Neurochir 161(8):1657-1667

34. Shrivastava RK, Sen C, Costantino PD, Della Rocca R (2005) Sphenoorbital meningiomas: surgical limitations and lessons learned in their long-term management. J Neurosurg 103(3):491-497

35. Talacchi A, De Carlo A, D’Agostino A, Nocini P (2014) Surgical management of ocular symptoms in spheno-orbital meningiomas. Is orbital reconstruction really necessary? Neurosurg Rev 37(2): 301-309

36. Terrier LM, Bernard F, Fournier HD, Morandi X, Velut S, Hénaux PL, Amelot A, François P (2018) Spheno-orbital Meningiomas surgery: multicenter management study for complex extensive tumors. World Neurosurg 112:e145-e156

37. Yannick N, Patrick F, Samuel M, Erwan F, Pierre-Jean P, Michel J, Stéphane V (2012) Predictive factors for visual outcome after resection of spheno-orbital meningiomas: a long-term review. Acta Ophthalmol 90(8):663-665

38. Yaşargil MG, Reichman MV, Kubik S (1987) Preservation of the frontotemporal branch of the facial nerve using the interfascial temporalis flap for pterional craniotomy. J Neurosurg 67(3):463-466

39. Zamanipoor Najafabadi AH, Peeters MCM, Lobatto DJ et al (2017) Health-related quality of life of cranial WHO grade I meningioma patients: are current questionnaires relevant? Acta Neurochir 159(11):2149-2159

40. Zamanipoor Najafabadi AH, Peeters MCM, Lobatto DJ, Groen JLG, Broekman MLD, Peerdeman SM, Peul WC, Taphoorn MJB, Dirven L, van Furth WR (2017) Impaired health-related quality of life of meningioma patients - a systematic review. NeuroOncology 17(9):897-907

41. Zoia C, Bongetta D, Gaetani P (2018) Endoscopic transorbital surgery for spheno-orbital lesions: how I do it. Acta Neurochir 160(6): $1231-1233$

Publisher's note Springer Nature remains neutral with regard to jurisdictional claims in published maps and institutional affiliations. 